\title{
PEMANFAATAN BUNGKIL BIJI KARET SEBAGAI EKSTENDER PEREKAT PADA KAYU LAPIS PULAI (Alstonia angustiloba Miq.)
}

\author{
M. I. Iskandar dan Achmad Supriadi* \\ Pusat Penelitian dan Pengembangan Hasil Hutan \\ Jl. Gunung Batu No. 5, Bogor 16610 \\ *e-mail : susupriadi@gmail.com
}

\author{
ABSTRACT \\ Bungkil Use as Seed Rubber Extender Gluten in Plywood Pulai \\ (Alstonia angustiloba miq. )
}

\begin{abstract}
Indonesia has the largest area of rubber trees in the world, in 2012 reached 3.5 million ha. As a producer of latex, rubber plant also produces lumber and rubber seeds. Rubber seeds have a starch content of $15.9 \%$, so have the opportunity to be made extenders as mixing the adhesive material. This study aimed to determine the utilization of rubber seed meal as an extender adhesives Urea Formaldehyde (UF) on plywood pulai. Extender material made with varying levels of 10\%, 20\% and 30\% respectively of the weight of the liquid adhesive. Variations intended use extenders levels in order to know the quality of plywood produced from a wide variety of levels of these extenders. The results showed that the average moisture content of plywood island $7.97 \%$, density of $0.485 \mathrm{~g} / \mathrm{cm} 3$, and the bonding strength of $11.36 \mathrm{~kg} / \mathrm{cm} 2$. The water content and the bonding strength of plywood pulai ware designed to meet the Indonesian National Standard. Statistically analysis levels extenders very significant effect on the bonding strength of plywood pulai. The higher levels of extenders, bonding strength of plywood pulai tends to decrease. Plywood pulai that has the best bonding strength value was the use of extender content of $10 \%$
\end{abstract}

Keywords: extenders, adhesives, rubber seed meal, plywood, quality pulai

\begin{abstract}
ABSTRAK
Indonesia memiliki areal tanaman karet terluas di dunia, pada tahun 2012 mencapai 3,5 juta ha. Sebagai penghasil getah, tanaman karet juga menghasilkan kayu dan biji karet. Biji karet memiliki kandungan pati $15,9 \%$, sehingga berpeluang untuk dibuat ekstender sebagai bahan pencampur perekat. Penelitian ini bertujuan untuk mengetahui pemanfaatan bungkil biji karet sebagai ekstender perekat Urea Formaldehida (UF) pada kayu lapis pulai. Bahan ekstender dibuat dengan kadar bervariasi yaitu $10 \%, 20 \%$ dan $30 \%$ masing-masing dari bobot perekat cair. Variasi penggunaan kadar ekstender bertujuan agar dapat diketahui mutu kayu lapis yang dihasilkan dari berbagai variasi kadar ekstender tersebut. Hasil penelitian menunjukkan bahwa rata-rata kadar air kayu lapis pulai 7,97 \%, kerapatan $0,485 \mathrm{gr} / \mathrm{cm}^{3}$, dan keteguhan rekat $11,36 \mathrm{~kg} / \mathrm{cm}^{2}$. Kadar air dan keteguhan rekat kayu lapis pulai yang dibuat memenuhi Standar Nasional Indonesia. Secara statistik kadar ekstender berpengaruh sangat nyata terhadap keteguhan rekat kayu lapis pulai. Makin tinggi kadar ekstender, keteguhan rekat kayu lapis pulai cenderung berkurang. Kayu lapis pulai yang memiliki nilai keteguhan rekat terbaik adalah yang menggunakan ekstender kadar $10 \%$.
\end{abstract}

Kata kunci : Ekstender, perekat, bungkil biji karet, kayu lapis, kualitas pulai

\section{PENDAHULUAN}

Indonesia memiliki areal tanaman karet terluas di dunia. Pada tahun 2013 diperkirakan luas areal tanaman karet di Indonesia mencapai 3.506 ha (SPKI, 2014). Banyaknya tanaman karet ratarata per hektar adalah 650 pohon (http://kebunimpianku.wordpress.com/2 010/08/20). Pengusahaan perkebunan karet dilakukan oleh tiga kelompok pelaku usaha yaitu Rakyat, Badan Usaha Milik Negara (BUMN) dan Swasta dengan sebaran luas dari tahun 2009 sampai 2013 disajikan pada Tabel 1. 
Tabel 1. Luas Perkebunan Karet Indonesia tahun 2009-2013 (dalam ribuan hektar)

\begin{tabular}{lrrrrr}
\hline Pengusahaan & \multicolumn{1}{c}{2009} & \multicolumn{1}{c}{2010} & \multicolumn{1}{c}{2011} & \multicolumn{1}{c}{2012} & \multicolumn{1}{c}{2013} \\
\hline Rakyat & 2,912 & 2,922 & 2,932 & 2,978 & 3,016 \\
BUMN & 239 & 239 & 257 & 259 & 261 \\
Swasta & 284 & 284 & 267 & 269 & 279 \\
Jumlah & 3.435 & 3.445 & 3.456 & 5.506 & 3.556 \\
\hline
\end{tabular}

Pada Tabel 1. Tampak bahwa pada tahun 2013 luas areal perkebunan karet di Indonesia mencapai 5.556.000 ha, dengan luas areal tertinggi diusahakan oleh rakyat $(85 \%)$, berikutnya oleh swasta $(8 \%)$ dan BUMN (7 \%). Komoditas utama yang dihasilkan oleh tanaman ini adalah getah karet. Selain penghasil getah, tanaman karet juga penghasil limbah kayu terutama pada tanaman yang telah tua (tidak produktif) dan penghasil biji karet.

Biji karet karet mengandung zat karbohidrat yang cukup tinggi yakni sekitar 15,9 \% (www.temp.co/read/ news/2013/05) dan bungkil biji karet juga belum dimanfaatkan sebagai ekstender pada industri kayu lapis, sehingga berpeluang untuk dibuat ekstender sebagai campuran perekat. Perekat sebagai bahan pembantu pada industri kayu lapis mempunyai peranan penting dalam merekatkan lembaran venir menjadi kayu lapis. Jenis perekat yang biasa digunakan pada industri kayu lapis di Indonesia adalah Urea Formaldehida (UF) dan Phenol Formaldehida $(\mathrm{PF})$. Jenis perekat mana yang akan digunakan tergantung kepada tujuan penggunaan dari produk yang dihasilkan. Untuk kayu lapis tipe interior menggunakan jenis perekat UF dan untuk kayu lapis tipe eksterior menggunakan PF. Perekat merupakan faktor yang turut menentukan mutu kayu lapis, di mana adonan perekat yang digunakan mempengaruhi mutu kayu lapis yang dibuat. Untuk menghemat pemakaian perekat, dapat ditambahkan ekstender ke dalam perekat tersebut, sehingga dapat mengurangi biaya penggunaan perekat. Pencampuran ekstender diharapkan tidak akan mengurangi kemampuan dan kekuatan daya rekat dari perekat yang digunakan. Tulisan ini menyajikan hasil penelitian mengetahui pemanfaatan bungkil biji karet sebagai ekstender perekat Urea Formaldehida (UF) pada kayu lapis pulai. (Alstonia angustiloba Miq.)

Bahan ekstender yang digunakan berupa bungkil biji karet dengan kadar bervariasi yaitu $10 \%, 20 \%$ dan $30 \%$ masing-masing dari bobot perekat cair. Sebagai kontrol digunakan perekat yang sama tanpa ekstender (kadar $0 \%$ ). Variasi penggunaan kadar ekstender bertujuan agar dapat diketahui kayu lapis yang dihasilkan dari berbagai kadar ekstender tersebut yang memenuhi persyaratan keteguhan rekat kayu lapis dan mengetahui kadar ekstender yang menghasilkan kayu lapis dengan keteguhan rekat terbaik.

\section{BAHAN DAN METODA}

\section{Bahan dan Alat}

Venir yang digunakan dalam penelitian ini adalah venir kupas dari kayu pulai sebanyak 100 lembar dengan ukuran panjang $20 \mathrm{~cm}$, lebar $20 \mathrm{~cm}$ dan tebal $1,5 \mathrm{~mm}$ serta kadar air $10 \%$. Perekat yang digunakan adalah Urea Formaldehida (UF) berasal dari PT Pamolite Adhesive Indsutry (PAI) Probolinggo, dengan spesifikasi kenampakan putih bening, kekentalan 1,2 poise, $\mathrm{pH} 10$ dan resin content $40 \%$, semuanya pada suhu $30{ }^{\circ} \mathrm{C}$. Bahan ekstender yang digunakan adalah biji karet, sekitar $500 \mathrm{~g}$ berupa bungkil. Ukuran bungkil 200 mesh.

Peralatan yang digunakan meliputi viscosimeter, oven, gelas ukur, timbangan, thermometer, alat uji geser tarik, gergaji mesin meja, mesin kempa panas dan dingin, caliper, kuas, pengaduk dan lain-lain. 


\section{Metode}

1. Persiapan bahan ekstender

Bungkil biji karet dijemur sampai mencapai kadar air kering udara, ditumbuk sampai halus, dikeringkan di oven sampai mencapai kadar air $12 \%$. Kemudian disaring menggunakan penyaring berukuran 200 mesh dan hasilnya disimpan dalam kantong plastic

\section{Pembuatan campuran perekat}

Komposisi perekat yang digunakan dalam penelitian dibuat dengan mencampur bahan-bahan seperti tercantum pada Tabel 2.

Pencampuran bahan dilakukan melalui tahapan sebagai berikut :

a. Perekat UF dimasukkan ke dalam gelas ukur

b. Ditambahkan bahan ekstender masing-masing sebanyak $10 \%, 20$ $\%$ dan $30 \%$ dari berat campuran perekat, kemudian diaduk secara perlahan sampai merata. Penambahan air pada setiap komposisi perekat terus dilakukan sambil diukur menggunakan viscosimeter sampai campuran mencapai kekentalan 18-20 poise.

c. Kemudian pada campuran tersebut ditambahkan pengeras (Amonium klorida) sebanyak $0,5 \mathrm{~g}$, lalu diaduk kembali hingga merata. Campuran ini siap untuk digunakan.

\section{Pembuatan kayu lapis}

Pembuatan kayu lapis dilakukan melalui tahapan sebagai berikut :

a. Venir ukuran $20 \mathrm{~cm} \quad$ x $20 \mathrm{~cm}$ diampelas agar mempunyai per- mukaan halus, kemudian dikeringkan dalam oven sampai mencapai kadar air $10 \%$

b. Permukaan venir dilaburi dengan campuran perekat secara single layer dengan berat labur $170 \mathrm{~g} / \mathrm{m} 2$ atau 13,6 g untuk setiap lembar kayu lapis berukuran $20 \mathrm{~cm} \times 20$ $\mathrm{cm}$.

c. Susun venir yang telah selesai dilabur secara bersilangan tegak lurus, dikempa dingin selama 10 menit dan dilanjutkan dengan kempa panas pada suhu $110{ }^{\circ} \mathrm{C}$ selama 3 menit.

4. Pembuatan contoh uji kadar air, kerapatan dan keteguhan rekat

Pembuatan contoh untuk pengujian mutu kayu lapis yang meliputi kadar air, kerapatan dan keteguhan rekat kayu lapis tersebut dilakukan 14 hari setelah kayu lapis selesai dibuat. Prosedur pengujian menurut Standar Nasional Indonesia (SNI, 2002).

\section{Analisis Data}

Untuk mengetahui pengaruh kadar ekstender terhadap kadar air, kerapatan keteguhan rekat kayu lapis pulai, maka dilakukan penelitian dengan Rancangan Acak Lengkap berfaktor tunggal (Sudjana, 2004). Sebagai perlakuan (faktor) adalah kadar ekstender yang terdiri dari 3 tingkat yaitu $10 \%, 20 \%$ dan $30 \%$. Pada setiap perlakuan dilakukan 4 (empat) kali ulangan, bahan ekstender berupa bungkil biji karet.

Tabel 2. Bahan Ramuan yang Dicampur ke dalam Perekat Urea Formaldehida

\begin{tabular}{|c|c|c|c|c|}
\hline \multirow[t]{2}{*}{ No } & \multirow[t]{2}{*}{ Komponen } & \multicolumn{3}{|c|}{ Kadar bahan ekstender (\%) } \\
\hline & & 10 & 20 & 30 \\
\hline 1 & Perekat urea formaldehida & 100 & 100 & 100 \\
\hline 2 & Ekstender & 10 & 20 & 30 \\
\hline 3 & Pengeras, $\mathrm{NH}_{4} \mathrm{Cl}$ & 0,5 & 0,5 & 0,5 \\
\hline & Jumlah & 110,5 & 120,5 & 130,5 \\
\hline
\end{tabular}


Model umum dari rancangan acak lengkap yang digunakan adalah :

$$
Y i j=+\alpha i+\varepsilon i j
$$

Keterangan :

Yij = Nilai pengamatan satuan percobaan pada perlakuan ke- I ulangan $\mathrm{ke}-\mathrm{j}$

$=$ Nilai rata-rata

$\alpha \mathrm{i}=$ Pengaruh perlakuan $\mathrm{ke}-\mathrm{i}$

$\varepsilon i \mathrm{j}=$ Kesalahan percobaan akibat perlakuan ke - i ulangan ke - j

$\mathrm{i}=1,2,3$ (banyak perlakuan)

$\mathrm{j}=1,2,3,4$ (banyak ulangan)
Nilai rata-rata keteguhan rekat kayu lapis dibandingkan dengan Standar Nasional Indonesia (SNI) mengenai mutu kayu lapis. Pengolahan data dilakukan dengan bantuan program Minitab (Hendradi, 2006).

\section{HASIL DAN PEMBAHASAN}

Hasil pengujian mutu kayu lapis disajikan pada Tabel 3 dan Gambar 1. Untuk mengetahui pengaruh kadar ekstender terhadap mutu kayu lapis pulai dilakukan analisis keragaman dan hasilnya disajikan pada Tabel 4.

Tabel 3. Nilai Rata-rata Mutu Kayu Lapis Pulai

\begin{tabular}{|c|c|c|c|c|c|c|}
\hline \multirow[t]{2}{*}{ No } & \multirow[t]{2}{*}{ Parameter mutu } & \multicolumn{4}{|c|}{ Kadar ekstender, \% } & \multirow[b]{2}{*}{ Rata-rata } \\
\hline & & 0 & 10 & 20 & 30 & \\
\hline 1 & Kadar air $(\%)$ & $\begin{array}{c}7,76 \\
(0,128)\end{array}$ & $\begin{array}{c}7,85 \\
(0,260)\end{array}$ & $\begin{array}{l}7,91 \\
(0,254)\end{array}$ & $\begin{array}{l}8,15 \\
(0,048)\end{array}$ & 7,92 \\
\hline 2 & $\operatorname{Kerapatan}\left(\mathrm{g} / \mathrm{cm}^{3}\right)$ & $\begin{array}{c}0,475 \\
(0,006)\end{array}$ & $\begin{array}{c}0,480 \\
(0,000)\end{array}$ & $\begin{array}{l}0,485 \\
(0,006)\end{array}$ & $\begin{array}{l}0,490 \\
(0,008)\end{array}$ & 0,48 \\
\hline 3 & $\begin{array}{l}\text { Keteguhan rekat } \\
\left(\mathrm{g} / \mathrm{cm}^{2}\right)\end{array}$ & $\begin{array}{c}8,54 \\
(0,343)\end{array}$ & $\begin{array}{l}12,55 \\
(0,411)\end{array}$ & $\begin{array}{r}11,20 \\
(0,192)\end{array}$ & $\begin{array}{r}10,33 \\
(0,158)\end{array}$ & 11,36 \\
\hline
\end{tabular}

Keterangan: Angka dalam kurung adalah simpangan baku

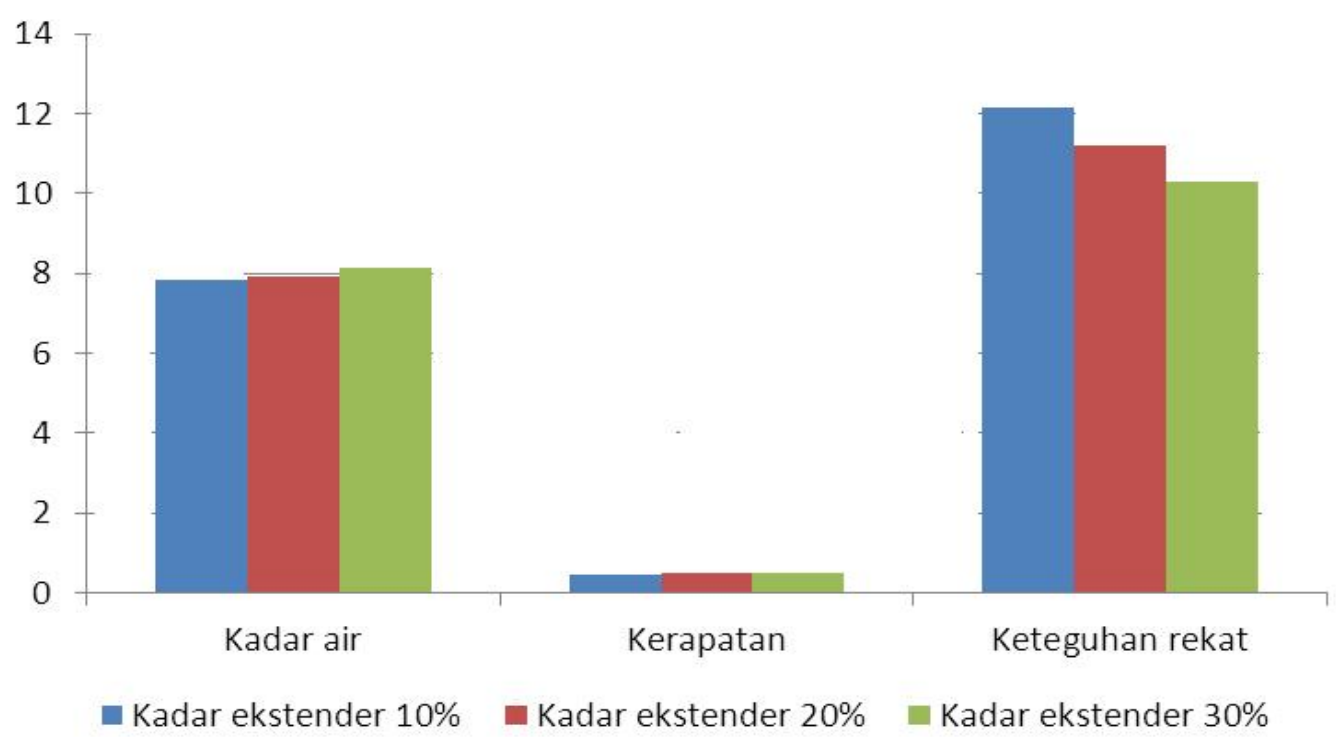

Gambar 1. Nilai Rata-rata Mutu Kayu Lapis Pulai pada Tiga Variasi Kadar Ekstender 
Tabel 4. Analisis Keragaman Pengaruh Kadar Ekstender terhadap Mutu Kayu Lapis Pulai

\begin{tabular}{llrrr}
\hline No. & \multicolumn{1}{c}{ Parameter mutu } & $\mathrm{db}$ & Kuadrat tengah & F hitung \\
& & & & \\
\hline 1 & Kadar air $(\%)$ & 3 & 0,1123 & 2,97 \\
& Kadar ekstender & 12 & 0,0378 & \\
& Galat & & & \\
2 & Kerapatan $\left(\mathrm{g} / \mathrm{cm}^{3}\right)$ & 3 & 0,00017 & $5,0^{*}$ \\
& Kadar ekstender & 12 & 0,00003 & \\
& Galat & & & \\
Keteguhan rekat $\left(\mathrm{g} / \mathrm{cm}^{2}\right)$ & 3 & 11,3337 & $130,00^{*}$ \\
& Kadar perekat & 12 & 0,0872 & \\
& Galat & &
\end{tabular}

Keterangan: $\mathrm{db}=$ derajat bebas, $*=$ nyata, $* *=$ sangat nyata

Kadar air kayu lapis pulai yang dibuat berkisar antara 7,76\% hingga $8,15 \%$ dengan rata-rata $7,92 \%$ (Tabel 3). Dengan demikian kayu lapis pulai tersebut semuanya memenuhi persyaratan Standar Nasional Indonesia atau SNI (2002), karena nilainya di bawah $14 \%$. Secara statistik kadar ekstender tidak berpengaruh nyata terhadap kadar air kayu lapis pulai (Tabel 4).

Kerapatan kayu lapis damar yang dibuat berkisar antara $0,47 \mathrm{~g} / \mathrm{cm}^{3}$ hingga $0,49 \mathrm{~g} / \mathrm{cm}^{3}$ dengan rata-rata $0,485 \mathrm{~g} / \mathrm{cm}^{3}$ (Tabel 3). Pada SNI tidak mensyaratkan besarnya kerapatan untuk kayu lapis. Makin tinggi kadar ekstender, semakin tinggi nilai kerapatannya. Hasil sidik ragam pada Tabel 4 menunjukkan kadar ekstender berpengaruh nyata terhadap kerapatan kayu lapis pulai. Hasil penelitian ini serupa dengan hasil penelitian pada Karakteristik bahan ekstender dalam pembuatan kayu lapis sengon (Iskandar \& Santoso, 2002), Penggunaan ekstender tepung biji alpukat (Iskandar \& Supriadi, 2015). Hasil uji beda lebih lanjut menunjukkan terdapat perbedaan nyata nilai kerapatan kayu lapis pulai antara yang tidak diberi ekstender dengan yang diberi ekstender (Tabel 5).

Keteguhan rekat kayu lapis pulai berkisar antara $8,54 \mathrm{~g} / \mathrm{cm}^{3}$ hingga 12,55 $\mathrm{g} / \mathrm{cm}^{2}$ dengan rata-rata $11,36 \mathrm{~g} / \mathrm{cm}^{2}$ (Tabel 3). Dengan demikian keteguhan rekat kayu lapis pulai tersebut semuanya memenuhi persyaratan Standar Nasional Indonesia karena rata-rata nilai keteguhan rekatnya lebih dari $7 \mathrm{~kg} / \mathrm{cm}^{2}$. Hasil sidik ragam pada Tabel 3 menunjukkan kadar ekstender berpengaruh sangat nyata terhadap keteguhan rekat kayu lapis pulai. Makin banyak penambahan ekstender pada ramuan perekat, keteguhan rekat kayu lapis semakin menurun. Hal ini terjadi karena makin tingginya kadar ekstender dalam campuran perekat, maka makin sedikit jumlah Urea Formaldehida per satuan luas permukaan venir, sehingga akan memperlemah ikatan antara perekat dengan venir kayu lapis. Hasil uji beda lebih lanjut menunjukkan terdapat perbedaan sangat nyata nilai keteguhan rekat kayu lapis pulai antara kontrol (tidak menggunakan ekstender) dengan yang menggunakan ekstender (Tabel 5). 
Tabel 5. Uji Beda terhadap Rata-Rata Keteguhan Rekat Kayu Lapis

No Parameter mutu Perbandingan nilai rata-rata

\begin{tabular}{|c|c|c|c|c|c|}
\hline 1 & Kerapatan $\left(\mathrm{g} / \mathrm{cm}^{3}\right)$ & $\begin{array}{c}\text { P0 } \\
0,475 \\
\mathrm{a}\end{array}$ & $\begin{array}{c}\text { P1 } \\
0,480 \\
\text { ab }\end{array}$ & $\begin{array}{c}\mathrm{P} 2 \\
0,485 \\
\mathrm{ab}\end{array}$ & $\begin{array}{c}\mathrm{P} 3 \\
0,490 \\
\mathrm{bc}\end{array}$ \\
\hline 2 & $\begin{array}{l}\text { Keteguhan rekat } \\
\left(\mathrm{kg} / \mathrm{cm}^{2}\right)\end{array}$ & $\begin{array}{l}8,54 \\
a\end{array}$ & $\begin{array}{c}12,55 \\
\mathrm{~d}\end{array}$ & $\begin{array}{c}11,20 \\
\mathrm{c}\end{array}$ & $\begin{array}{c}10,33 \\
b\end{array}$ \\
\hline
\end{tabular}

Hasil ini serupa dengan hasil penelitian Perry (1947) dalam Iskandar dan Santoso, (2002) yang menyatakan bahwa penambahan bahan pengisi dalam campuran perekat lebih dari $10 \%$ dari berat perekat menyebabkan penurunan keteguhan rekat, walaupun hasilnya masih baik. Santoso dan Sutigno, (2004) yang meneliti tentang Pengaruh bungkil gaplek dan dekstrin sebagai ekstender perekat Urea Formaldehida terhadap keteguhan rekat kayu lapis kapur, Siruru (2006) tentang Pengaruh ekstender dan bahan pengisi perekat Urea Formaldehida terhadap delaminasi papan blok, Sari et al. (2008) yang meneliti tentang penggunaan bungkil buah nipah ( $N y f a$ Fruticans Wurmb) sebagai ekstender pada perekat Urea Formaldehida untuk papan partikel, Santoso et al., (2010) yang meneliti Pengaruh kadar ekstender dan waktu kempa terhadap sifat fisis mekanis LBV dengan perekat Phenol Formaldehida, juga serupa dengan hasil penelitian Pengaruh ekstender tepung biji alpukat (Iskandar \& Supriadi, 2015). Kayu lapis pulai yang memiliki nilai keteguhan rekat terbaik adalah dengan ekstender kadar $10 \%$.

Untuk mengetahui hubungan antara kadar ekstender dengan keteguhan rekat kayu lapis pulai, dilakukan sidik regresi (Tabel 5). Hasilnya adalah $\mathrm{Y}=13,59-$ $0,11 \mathrm{X}$. Hubungan tersebut berupa regresi linier. Nilai koefisien regresi bertanda negatif. Hal ini berarti makin tinggi kadar ekstender, keteguhan rekat kayu lapis makin rendah dan sebaliknya. Nilai F 116,87 menunjukkan bahwa kadar ekstender berpengaruh sangat nyata terhadap keteguhan rekat kayu lapis, $\mathrm{R}^{2}$ sebesar 0,92 menunjukkan bahwa variabel kadar ekstender dapat menjelaskan variabel keteguhan rekat sebesar 92\%. Hubungan regresi pada penelitian ini serupa dengan hasil penelitian Wahyuningsih (1985) tentang Pengaruh campuran sagu dan bungkil biji karet sebagai ekstender Urea Formaldehida terhadap keteguhan rekat kayu lapis meranti merah, Santoso dan Sutigno, (2004) tentang Pengaruh bungkil gaplek dan dekstrin sebagai ekstender perekat Urea Formaldehida terhadap keteguhan rekat kayu lapis kapur, dan Iskandar dan Supriadi, (2015) tentang Pengaruh kadar ekstender bungkil biji alpukat terhadap mutu kayu lapis damar.

\section{KESIMPULAN}

1. Luas areal tanaman karet tahun 2013 di Indonesia 3,6 juta hektar, sekitar $85 \%$ diusahakan oleh Rakyat.

2. Biji karet memiliki kandungan pati $15,9 \%$, sehingga berpeluang untuk dibuat ekstender sebagai bahan pencampur perekat,

3. Semua kayu lapis pulai yang dibuat memenuhi standar SNI.

4. Kayu lapis pulai yang dibuat memiliki rata-rata kadar air 7,97\%, kerapatan 0,485 $\mathrm{gr} / \mathrm{cm} 3$, dan keteguhan rekat $11,36 \mathrm{~kg} / \mathrm{cm}^{2}$.

5. Kadar ekstender berpengaruh sangat nyata terhadap keteguhan rekat kayu lapis. Makin tinggi kadar ekstender, semakin menurun keteguhan rekat kayu lapis pulai. Hubungan antara kadar ekstender 
dengan keteguhan rekat berupa regresi linier yang dinyatakan sebagai $\mathrm{Y}=13,59-0,11 \mathrm{X}$.

6. Dengan pertimbangan lebih ekonomis, disarankan untuk menggunakan perekat dengan kadar ekstender $30 \%$.

\section{DAFTAR PUSTAKA}

Badan Standardisasi Nasional. 2002. SNI 01-5008.2-2000. Kayu lapis penggunaan umum. Jakarta: Badan Standardisasi Nasional.

Hendradi, T.C. 2006. Statistik Six Sigma dengan Minitab. Panduan Cerdas Inisiatif Kualitas. Yogyakarta: ANDI OFFSET.

http://kebunimpianku.wordpress.com/20 10/08/20/perkiraan-biayaberkebun. Diakses tanggal 24 Nopember 2015

Iskandar, M.I. 2003. Kualitas tiga macam bahan pengisi dalam pembuatan kayu lapis mangium. Prosiding Ekspose Hasil-hasil Litbang Hasil Hutan dalam mendukung program Restrukturisasi Kehutanan, 53-58. Bogor: Puslitbang Teknologi Hasil Hutan.

Iskandar, M.I. \& A. Santoso. 2002. Karakteristik bahan ekstender dalam pembuatan kayu lapis sengon. Prosiding Seminar Nasional ke V MAPEKI, 290295. Bogor: Masyarakat Peneliti kayu Indonesia.

Iskandar, M.I. \& A. Supriadi .2015. Pengaruh kadar ekstender bungkil biji alpukat terhadap mutu kayu lapis damar. Jurnal
Penelitian Hasil Hutan 28 (4), 380-393.

Santoso, A., Hadi, Y.S., \& Juliati, R. 2010. Pengaruh kadar ekstender dan waktu kempa terhadap sifat fisis mekanis LBV dengan perekat phenol formaldehida. Jurnal Penelitian Hasil Hutan 28 (4), 380-393.

Santoso, A. dan P.Sutigno. 2004. Pengaruh bungkil gaplek dan dekstrin sebagai ekstender perekat Urea Formaldehida terhadap keteguhan rekat kayu lapis kapur. Jurnal Penelitian Hasil Hutan 22 (2), 61-68.

Sari, M.N., Rosidah dan Rahman, Y.M. 2008. Jurnal Ilmu Kehutanan 2 (1), 48-54

Siruru, H. 2006. Pengaruh ekstender dan bahan pengisi perekat Urea Formaldehida terhadap delaminasi papan blok. Jurnal Agroforestri 1 (3), 19-25.

SPKI. 2014. Luas Areal Perkebunan Karet Indonesia. Jakarta. Direktorat Jenderal Perkebunan Indonesia.

Sudjana. 2004. Desain dan Analisis Eksperimen. Bandung: Tarsito.

Wahyuningsih, E. 1985. Pengaruh campuran sagu dan bungkil biji karet sebagai ekstender Urea Formaldehida terhadap keteguhan rekat kayu lapis meranti merah. Bogor: Fahutan IPB. Skripsi (Tidak diterbitkan).

www.temp.co/read/news/2013/05 Renyahnya es krim dari biji karet. Diakses tanggal 18 Juni 2015. 